\title{
Entrepreneurial Leadership and Organization Innovation: Effect of Knowledge Management and Organizational Climate
}

\author{
Muhdiyanto $^{1}$, Ahyar Yuniawan ${ }^{2}$ \\ \{muhdiyanto@ummgl.ac.id ${ }^{1}$ \} \\ Doctoral student of Diponegoro University, Semarang ${ }^{1}$ \\ Diponegoro University, Semarang ${ }^{2}$
}

\begin{abstract}
The purpose of this paper is to examine the effects of entrepreneurial leadership and knowledge management on organizational innovation of small-medium enterprises (SMEs) as well to determine whether organizational climate moderates the mediating effect of knowledge management in the entrepreneurial leadership and organizational innovation relationship. The study was carried out on the base questionnaire survey among 115 SME owners of Magelang. The analysis tool uses Structural Equation Modeling (SEM) in testing hypotheses and through the Warp PLS program. The empirical findings indicate that entrepreneurial leadership and knowledge management positively influence organizational innovation. But contrary to the prediction, the result indicates that the moderation and moderated mediation relationship are weaker under an organizational climate.
\end{abstract}

Keywords: Entrepreneurial leadership, knowledge management, organizational innovation, organizational climate

\section{Introduction}

Organizational innovation in small and medium enterprises is very important. According to Wang and Wang [41], organizational innovation will enhance organizational performance and competitive advantage [40]. Of course, small and medium enterprises that are unable to adapt to the environment through innovation, the survival of these organizations can be threatened. Several studies have explored related to organizational innovation [1][9][16]. Organizational innovation is the process of creating ideas, new processes, and new products related to organizational sustainability. Innovation needs to be managed in accordance with the structure, culture and logic of the organization coupled with the right strategy [30], thus increasing efficiency and performance [12].

Organizational innovation is also the ability to respond to internal and external opportunities, through creative efforts to introduce new ideas, processes, or products and services. Employee engagement is a key factor in organizational innovation, particularly in small and medium enterprises, through creative contributions to process, product and organizational development [7]. Spread of creative ideas from employees for continuous improvement of organizational performance. This process can be seen as the evolution of organizational integration, and technology with a series of iterative activities [2], such as the search, selection, application of new innovative ideas into processes, products and 
organizations. Employee creativity and innovation in small and medium enterprises requires encouragement from creative leaders [2]. According to Bagheri and Harrison [4], a creative leader is identified with leadership who has an entrepreneurial spirit. This leadership emphasizes more on basic characters, such as a vision that is far ahead and used as a driver of change and combines various resources to get something new. This type of leadership is needed in an organization to anticipate various changes, especially in small and medium enterprises.

The process of transforming entrepreneurial leadership in encouraging organizational innovation requires good knowledge management [12]. According to Kmieciak and Michna [22] knowledge management is the process of transforming information and intellectual assets into enduring value in an organization. A good knowledge management system will ensure the proper application of knowledge, thereby increasing ideas, innovation, thinking, competence and expertise that have an impact on organizational effectiveness. The ability to transfer knowledge, of course, requires intelligent leadership, so that it can transform organizational values in subordinates. When a creative leader is accompanied by good share cognitive abilities to subordinates, a high level of innovation is encouraged in an organization. Of course, a leader's expertise in transforming information is key in an organization.

The success of a leader's knowledge transformation process also requires a supportive organizational climate [26]. Organizational climate will determine motivation and perceptions of values in the organization. Of course, the transfer of knowledge of the leader to his subordinates is effective, if the perceptions and values are in accordance with those of the subordinates so as to encourage organizational innovation effectively [14][21][29]. This shows that, the organizational climate determines the success process in transferring knowledge to organizations, especially in small and medium enterprises [34].

Various empirical evidence shows that, entrepreneurial leadership has an effect on organizational innovation [1]-[3][18][27][33]. However, different results indicate that entrepreneurial leadership has an effect on the innovation process but not on innovation performance [13]. Entrepreneurial leadership only affects the process of achieving innovation, but does not necessarily result in effective innovation. This process certainly does not have an effective impact on the organization. Seeing the context, according to Chen, Huang, and Hsiao [6], knowledge management is a key factor in encouraging innovation and is also determined by the role of creative leadership in organization [4]. In addition, organizational climate also determines the successful process of knowledge transformation in organizational innovation [14][16][18][21][26][34].

There are several interesting reasons for researchers to study this research. First, the influence of entrepreneurial leadership on organizational innovation still produces controversial results [1][2][3][13]. Second, research places knowledge management as a mediating variable and organizational climate as a moderating variable, because the organizational innovation process depends on the leader in the transformation process and it depends on the organizational climate.

\section{Literature Review}

\subsection{Organizational innovation}

Organizational ability to innovate, one of the conditions for the successful use of new resources and technology. Organizational innovation is an idea, item, event, method, which is 
felt or observed as something new to a person or group of people (society), whether it is in the form of inventions or disk conversion [6]. While, Hueske, Endrikat, and Guenther [19] shows that, organizational innovation as the successful application of creative ideas in companies, organizational mechanisms to adapt in dynamic environments. Therefore, the organization must be able to create assessments as well as new ideas and offer innovative products. Innovation is a tool for developing organizations, through the introduction of new technologies, new applications, services, development and new organizational structures. Integration of various aspects of innovation, thus creating organizational innovation. The innovation that occurs in an organization is a process of progress of the organization, but various obstacles and obstacles will occur when the innovation starts to enter the organization. By understanding the innovation process in the organization, it will be able to reduce organizational shock in implementing innovation diffusion.

According to Damanpour [8], organizational innovation as the development and use of new ideas or behaviors related to new products, services, markets, and administration. Osborne and the innovation process in three main stages, namely the invention stage, implementation stage, and diffusion stage. While, Hamdoun et al. [16] simplifies the innovation process in three main steps, namely producing ideas, evaluating ideas, and implementing ideas. Broadly speaking, the stages of innovation are formulated into three main stages, namely the process of initiation, adoption, and implementation.

\subsection{Entrepreneurial leadership}

Entrepreneurial leadership is the ability of a leader to organize a group of people who work in their organization to achieve common goals, through proactive behavior, dare to take risks, innovate to take advantage of opportunities, take personal responsibility, and manage change for the benefit of the organization [33]. Based on this definition, entrepreneurial leadership includes three dimensions, namely opportunity seekers, risk takers, and resource allocators. Integrating these three dimensions, entrepreneurial leadership is effective in driving organizational innovation.

Entrepreneurial leadership is also capable of being a mentor to subordinates related to organizational development, both in the technical and organizational management fields [33]. Entrepreneurial leadership always awakens individuals, teams and organizations, to achieve goals in the organization. Furthermore, entrepreneurial leadership always instills confidence to think, behave and act in an entrepreneurial way, the development of the organization and the stakeholders involved. Of course, this ability is very suitable for leadership in small and medium enterprises with consideration of the low ability of resources, both human and other resources. In addition, entrepreneurial leadership always involves employees through the contribution of energy and thoughts, so that the company's targets can be realized collectively.

Empirical evidence shows that entrepreneurial leadership has an effect on organizational innovation [1]-[3][18][33]. This shows that, when a leader has the courage to take risks, involve and guide employees, it will encourage subordinates to increasingly innovate in the organization, through the creation of new ideas and ideas to develop the organization. Based on this concept, it is hypothesized as follows:

\section{H1. Entrepreneurial leadership affects organizational innovation}




\subsection{Knowledge management}

Knowledge management is a process that helps organizations identify, select, organize, disseminate and transfer important information and experiences that are part of the organization [38]. Knowledge Management helps absorb knowledge and insights to maintain organizational sustainability. According to Nonaka and Takeuchi [28] knowledge is dynamic and can change form from tacit to explicit or vice versa. Tacit knowledge is a form of knowledge that is contained in a person's brain or mind according to the person's own understanding and experience. Usually this knowledge is unstructured, difficult to define and convey in formal language to others and its content includes personal understanding. Meanwhile, explicit knowledge is knowledge that has been collected and translated into a form of documentation, making it easier for others to understand. This knowledge is formal in nature and easy to share with others in the form of documentation, through books, articles and journals without having to come directly to teach that person.

Knowledge management involves three main factors, namely people, process and technology [12]. These three factors operate in an integrated manner. In principle, every organization must do Knowledge Management either consciously or not, so it must be done in a planned manner. When the organization does not understand this context, it will cause ineffectiveness and inefficiency on all fronts. Moreover, in small and medium enterprises, the competition is so tight. Knowledge management is not something better, but about knowing how to do something better.

The knowledge transformation process depends on the role of entrepreneurial leadership. When the creative leader, through the appearance of new ideas, will encourage a good knowledge management process. Empirical evidence shows that entrepreneurial leadership has an effect on knowledge management [5][31]. Furthermore, with a good knowledge transformation process, subordinates will create creative ideas so as to encourage good organizational innovation. The results showed that knowledge management has an effect on organizational innovation [6][9][12][16][22][25][32][38]. Based on this concept, it is hypothesized as follows:

H2. Entrepreneurial leadership affects knowledge management H3. Knowledge management affects organizational innovation

\subsection{Organizational Climate}

Organizational climate influences human resource practices and policies accepted by organizational members. Every organization will have a different organizational climate, determined by the diversity of jobs designed within the organization, or by the nature of the individual. According to Olsson et al. [29] Organizational climate as a form of collection and environmental patterns that encourage the emergence of motivation and perceptions that can be assessed, so that it has a direct influence on the performance of organizational members. An open organizational climate encourages employees to express interests and dissatisfaction without fear of retaliation and concern, thus encouraging members of the organization to have a high level of confidence and believe in fairness of action. Of course, it is important to create an organizational climate in organizations, especially in small and medium enterprises because it is used as the basis for determining the behavior of subsequent members.

Organizational climate will determine the process of transforming knowledge from leaders to organizational innovation [11][29][34]. When the organizational climate is supportive, the knowledge transformation process will run well. Knowledge management is formed a 
conducive learning environment, so that employees are motivated to learn continuously, utilize the information or knowledge provided by the organization, and develop their individual knowledge. Through these conditions, of course, it will facilitate the knowledge management process and accelerate the implementation process in organizations, especially in small and medium enterprises, so that institutionalizing and distributing knowledge becomes easier. Based on this concept, it is hypothesized as follows:

\section{H4. Organizational climate moderates the influence of entrepreneurial leadership on knowledge management \\ H5. Organizational climate moderates the influence of knowledge management on organizational innovation}

Schematically, the influence of entrepreneurial leadership and knowledge management on organizational innovation is moderated by organizational climate in Figure 1.

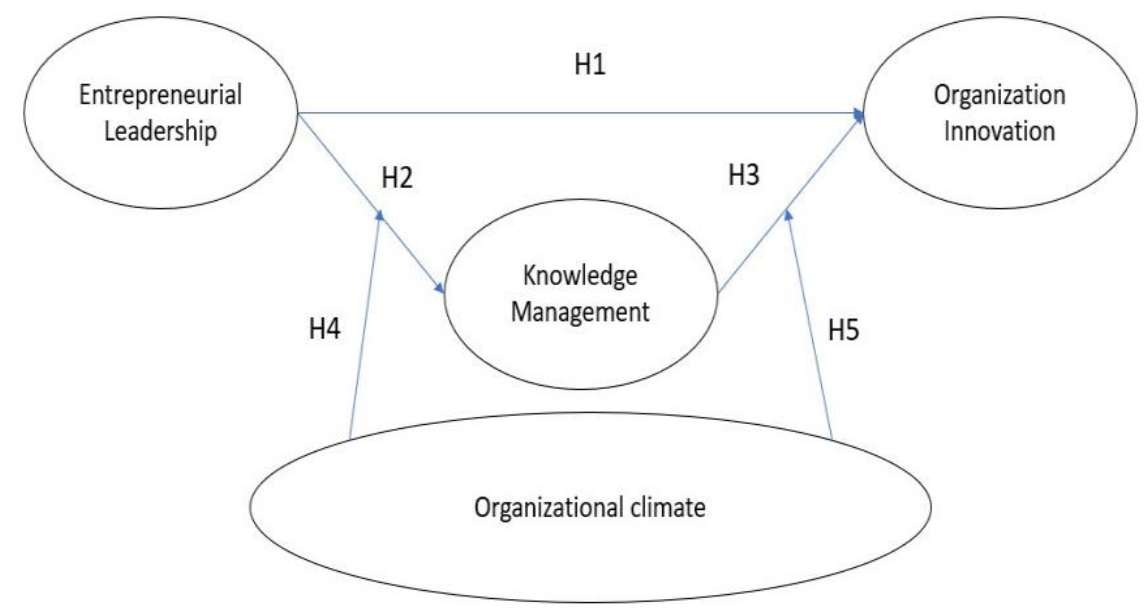

Fig. 1. The research models

\section{Methods}

\subsection{Samples and procedures}

The selection of the research setting is based on previous research, namely on small and medium enterprises [22]. This population is likely to have high innovation power, to maintain the continuity of its business. The population of this study is the leaders of Small and Medium Enterprises in the Magelang region. This research is a group analysis unit and the sample selection method is non-probabilistic sampling with purposive sampling technique [36]. The criteria in this study are leaders of small and medium enterprises with more than five employees [39].

The distribution of questionnaires in this study were 150 respondents and 133 returned (response rate $89 \%$ ), but those that can be used in this study are only 115 questionnaires. The remainder cannot be used due to incomplete answers and data. Based on this amount, this study fulfills the minimum sampling limit. Now and Bougie [17] say that, a sample size of more than 
30 and less than 500 is appropriate for research. Furthermore, Iovino and Tsitsianis [20] the minimum sampling limit is 100 respondents. A sample size that is too large or small will not help in the study.

The history of education consists of high school as many as 43 respondents, academies as many as 38 and Bachelor as many as 32 respondents. Furthermore, there are 2 respondents who filled others, namely junior high school educated. The age of respondents is less than 24 years as many as 12 respondents and the rest are more than equal to 24 years.

\subsection{Operational definition and variable measurement}

Organizational innovation is an idea, item, event, method, which is felt or observed as something new to a person or group of people (society), whether it is in the form of inventions or disk conversion [6]. This variable is measured by 4 question indicators that are adopted from Kmieciak, Michna, and Meczynska [23] with a five Likert scale, from 1 for strongly disagree to 5 for strongly agree. All indicators on the research variables showed validity and the results of the reliability test in this study showed Cronbach alpha of 0.799 .

Entrepreneurial leadership is the ability of a leader to organize a group of people who work in their organization to achieve common goals, through proactive behavior, dare to take risks, innovate to take advantage of opportunities, take personal responsibility, and manage change for the benefit of the organization [33]. This variable is measured by 8 question items with those developed by Renko, El Tarabishy, Carsrud, and Brännback [35], the Entrepreneurial Leadership Questionnaire with a five Likert scale, from 1 for strongly disagree to 5 for strongly agree. All indicators on the research variables showed validity and the reliability test results in this study showed Cronbach alpha of 0.783 .

Knowledge management is a process that helps organizations identify, select, organize, disseminate and transfer important information and experiences that are part of the organization [38]. This variable is measured by 5 question indicators that are adopted from Lee, Lee, and Kang [24] with five Likert scales, from 1 to strongly disagree to 5 to strongly agree. All indicators on the research variables show validity and the reliability test results in this study show Cronbach alpha of 0.784 .

Organizational climate as a form of collection and environmental patterns that encourages the emergence of motivation and perceptions that can be assessed, so that it has a direct influence on the performance of organizational members [29]. This variable is measured by 5 question indicators that are adopted from Shadur, Kienzle, and Rodwell [37] with a five Likert scale, from 1 for strongly disagree to 5 for strongly agree. All indicators in the research variables showed validity and the results of the reliability test in this study showed Cronbach alpha of 0.895 .

\subsection{Analysis tools}

The analytical tool in this study uses Structural Equation Modeling (SEM) in testing hypotheses and through the Warp PLS program [15]. Determining whether a model is fit or not in this research uses several measures, namely the average path coefficient (APC), average Rsquare (ARS) and average variance inflation factor (AVIF). APC and ARS values must be less than 0.05 and AVIF as an indicator of multicolinearity must be greater than 5 . 


\section{Results and Discussion}

\subsection{Result}

The results of the research model test show that the indicators of the model are fit and have been met, namely the APC and ARS are significant with a p value of less than 0.05. Likewise, the AVIF indicator is 1.138 and meets the requirements below 5 . This result is strengthened by an adjusted $\mathrm{R}$ square (R2) value of 0.27 , which means that the variation of organizational innovation variables (OIN) can be explained by variations of the three independent variables, namely entrepreneurial leadership (EL). knowledge management (KM), and organizational climate (OC) by $27 \%$, while the rest is explained by variables outside the model.

The direct effect of entrepreneurial leadership (EL) on organizational innovation (OIN) $f$ shows significant results $(\beta=0.20 ; \mathrm{p}<0.01)$, so that hypothesis $1(\mathrm{H} 1)$ is supported. Furthermore, the influence of entrepreneurial leadership (EL) on knowledge management (KM) shows a significant result $(\beta=0.48 ; \mathrm{p}<0.01)$ so that hypothesis $2(\mathrm{H} 2)$ is supported. Furthermore, knowledge management (KM) on organizational innovation (OIN) also shows significant results $(\beta=0.39 ; \mathrm{p}<0.01)$, so hypothesis $3(\mathrm{H} 3)$ is supported. In addition, the moderating effect of organizational climate on entrepreneurial leadership (EL) on knowledge management $(\mathrm{KM})$ shows insignificant results $(\beta=0.13 ; \mathrm{p}>0,01)$ and the moderating effect of organizational climate on the influence of knowledge management $(\mathrm{KM})$ on organizational innovation (OIN) shows insignificant results $(\beta=0.03 ; \mathrm{p}>0.01)$. This means that hypothesis 4 (H4) and hypothesis 5 (H5) are not supported. The overall test is shown in Figure 2.

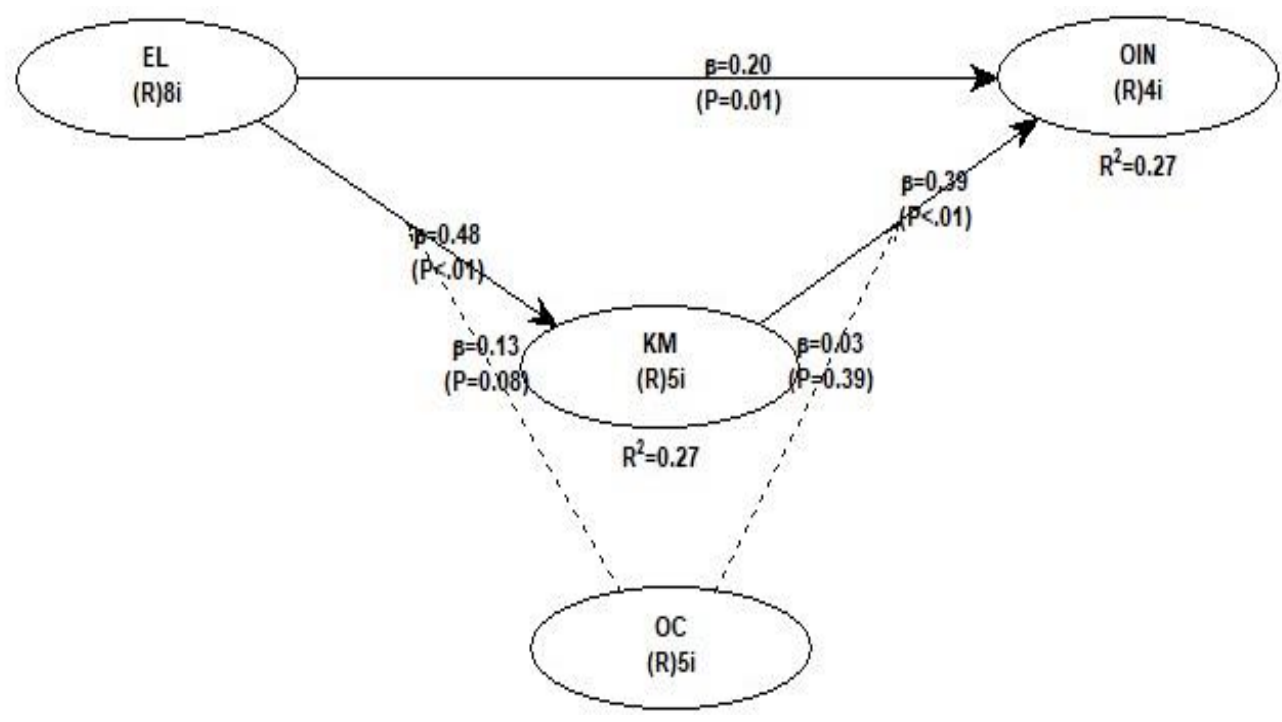

Fig. 2. Full Model

\subsection{Discussion}

This study examines the effect of entrepreneurial leadership on organizational innovation that is mediated by knowledge management and the moderating effect through organizational 
climate. The test results show that, the influence of entrepreneurial leadership on organizational innovation is significant, so that hypothesis 1 (H1) is supported. These results are consistent with research Akbari et al. [1]; Paudel [33]; Huang et al. [18]; Bagheri [2]; and Bagheri and Akbari [3] which shows that entrepreneurial leadership affects organizational innovation. When a leader has a high creative spirit and is brave enough to take risks, then encouraging organizational innovation is better. Moreover, small and medium enterprises really need a leadership style that has this creative power, because competition is so competitive and has limited resources. In addition, leaders must also be able to take advantage of existing opportunities to maintain the sustainability of the organization. Entrepreneurial leadership is always proactive in environmental dynamics, so that it can have a very good impact and differentiation on other organizations [5]. The existence of these new breakthroughs, so that organizations are more dynamic and responsive to environmental responses. Of course, leadership in small and medium enterprises is not only an agent of change, but also leads the change itself. Strategic leadership that has a high sense of business and sense of change, is able to act proactively, creatively and innovatively is what drives organizational innovation.

The results of testing the influence of entrepreneurial leadership on knowledge management are significant, so that hypothesis 2 (H2) is supported. These results certainly support the research Chaston [5] and Overall [31] which shows that entrepreneurial leadership has an effect on knowledge management. When a leader shows proactive and creative behavior, the knowledge transformation process will be better. This means that subordinates can quickly understand what the leadership says, so that organizational goals can be achieved. In addition, entrepreneurial leadership always involves a new model of thinking and action, starting with a fundamentally different world view of business and applying illogical decision making, also delivering flexible understanding of subordinates. This understanding, accelerates the process of knowledge transfer in organizations. The thinking principle that develops cognitive ambidexterity also leads to a better knowledge transformation process. This principle further emphasizes that, entrepreneurial leaders must rely on a varied analytical approach by complementing thought and action to create and implement solutions in a socially, environmentally, and economically sustainable manner. In addition, entrepreneurial leadership also uses predictive logic, the use of traditional analytical approaches, is an extension of the scientific method to think, evaluate, and then act to change an organization towards the goals set in the process of conveying knowledge to subordinates. This capability is very effective in the knowledge transformation process in organizations. environment, and a sustainable economy. In addition, entrepreneurial leadership also uses predictive logic, the use of traditional analytical approaches, is an extension of the scientific method to think, evaluate, and then act to change an organization towards the goals set in the process of conveying knowledge to subordinates. This capability is very effective in the knowledge transformation process in organizations. environment, and a sustainable economy. In addition, entrepreneurial leadership also uses predictive logic, the use of traditional analytical approaches, is an extension of the scientific method to think, evaluate, and then act to change an organization towards the goals set in the process of conveying knowledge to subordinates. This capability is very effective in the knowledge transformation process in organizations.

The results of testing the influence of knowledge management on organizational innovation are significant, so that hypothesis 3 (H3) is supported. These results certainly support the research Chen et al. [6]; Ferraresi et al. [12]; Kmieciak and Michna [22]; Slavković and Babić [38]; de Zubielqui et al. [9]; and Hamdoun et al. [16] which shows that knowledge management affects organizational innovation. When the knowledge transformation process is well understood by subordinates, then innovation in the organization is good too. The knowledge 
transfer process is in the form of tacit knowledge and explicit knowledge. An employee is able to understand the process of transferring knowledge independently and is able to properly document, will encourage creative and innovative ideas in the organization. Good knowledge management helps to obtain potential sources of information, so as to develop self-knowledge and increase the effectiveness of individual and organizational work. This ability is needed, especially for employees of small and medium enterprises.

The results of testing the moderating effect of organizational climate on the influence of entrepreneurial leadership on knowledge management are not significant and the moderating effect of organizational climate on the influence of knowledge management on organizational innovation is also not significant, so hypothesis 4 (H4) and hypothesis 5 (H5) are not supported. The results of this study are different from the research Olsson et al. [29]; Mafabi et al. [26]; and Donate and Guadamillas [10] which shows that the organizational climate does not moderate the influence of entrepreneurial leadership on knowledge management and on the influence of knowledge management on organizational innovation. This shows that, the organizational climate does not necessarily provide a good impetus for the knowledge transfer process in small and medium enterprises. According to Olsson et al. [29], organizational climate is the condition, condition and characteristics of the workplace environment which characterizes an organization which is formed from the attitudes, behavior and personalities of all members of the organization. Based on this concept, of course, the organizational climate requires a good understanding of a subordinate if it is to be successful. However, the low level of understanding of human resources in small and medium enterprises has no impact on organizational innovation. This is possible because the resources in small and medium enterprises are still low and the work atmosphere has not yet been formed, as in advanced organizations.

\section{Conclusions}

This study proposes 5 (five) hypotheses, but 3 (three) hypotheses are supported and 2 (two) hypotheses are supported. The influence of entrepreneurial leadership affects organizational innovation and knowledge management, so that $\mathrm{H} 1$ and $\mathrm{H} 2$ are supported. In addition, knowledge management also affects organizational innovation, so that $\mathrm{H} 3$ is also supported. Meanwhile, the moderation effect does not encourage the influence of entrepreneurial leadership on knowledge management and the influence of knowledge management on organizational innovation. This shows that hypothesis 4 (H4) and hypothesis 5 (H5) are not supported.

Based on the above conclusions, this study provides several recommendations. First, entrepreneurial leadership is very important in encouraging organizational innovation, so that creative and proactive leadership and seeing opportunities is needed in small and medium enterprises. In addition, conveying these ideas and ideas is expected to go through the process of good knowledge transformation, thus helping organizational innovation effectively. Second, the organizational climate in small and medium enterprises is still low, so that the perception of understanding of the goals and vision of the organization must be the same between leaders, subordinates and stakeholders, so that the organizational climate will be well formed in small and medium enterprises. Furthermore, respondents in this study answered self-report questionnaires, it is possible to have common method biases. 


\section{References}

[1] Akbari, M., Bagheri, A., Imani, S., \& Asadnezhad, M. (2020). Does entrepreneurial leadership encourage innovation work behavior? The mediating role of creativity self-efficacy and support for innovation. European Journal of Innovation Management.

[2] Bagheri, A. (2017). The impact of entrepreneurial leadership on innovation work behavior and opportunity recognition in high-technology SMEs. The Journal of High Technology Management Research, 28(2), 159-166.

[3] Bagheri, A., \& Akbari, M. (2018). The impact of entrepreneurial leadership on nurses' innovation behavior. Journal of Nursing Scholarship, 50(1), 28-35.

[4] Bagheri, A., \& Harrison, C. (2020). Entrepreneurial leadership measurement: a multi-dimensional construct. Journal of Small Business and Enterprise Development.

[5] Chaston, I. (2012). Entrepreneurship and knowledge management in small service-sector firms. The Service Industries Journal, 32(6), 845-860.

[6] Chen, C. J., Huang, J. W., \& Hsiao, Y. C. (2010). Knowledge management and innovativeness. International Journal of Manpower.

[7] Coleman, M. W. (2017). Understanding How Transformational Leaders Inspire Employee Engagement in Rapidly Changing Environments. (10744699 D.B.A.), Liberty University, Ann Arbor. Retrieved from https://search.proquest.com/docview/2021979479?accountid=49069 ProQuest Dissertations \& Theses Global database.

[8] Damanpour, F. (2017). Organizational innovation. In Oxford Research Encyclopedia of Business and Management.

[9] De Zubielqui, G. C., Lindsay, N., Lindsay, W., \& Jones, J. (2019). Knowledge quality, innovation and firm performance: a study of knowledge transfer in SMEs. Small Business Economics, 53(1), 145-164.

[10] Donate, M. J., \& Guadamillas, F. (2010). The effect of organizational culture on knowledge management practices and innovation. Knowledge and process management, 17(2), 82-94.

[11] Durcikova, A., Fadel, K. J., Butler, B. S., \& Galletta, D. F. (2011). Research note-knowledge exploration and exploitation: the impacts of psychological climate and knowledge management system access. Information Systems Research, 22(4), 855-866.

[12] Ferraresi, A. A., Quandt, C. O., dos Santos, S. A., \& Frega, J. R. (2012). Knowledge management and strategic orientation: leveraging innovativeness and performance. Journal of Knowledge Management.

[13] Fontana, A., \& Musa, S. (2017). The impact of entrepreneurial leadership on innovation management and its measurement validation. International Journal of Innovation Science.

[14] Glisson, C. (2015). The role of organizational culture and climate in innovation and effectiveness. Human Service Organizations: Management, Leadership \& Governance, 39(4), 245-250.

[15] Hair, J. F., Ringle, C. M., \& Sarstedt, M. (2011). PLS-SEM: Indeed a silver bullet. Journal of Marketing Theory and Practice, 19(2), 139-152.

[16] Hamdoun, M., Jabbour, C. J. C., \& Othman, H. B. (2018). Knowledge transfer and organizational innovation:

[17] Impacts of quality and environmental management. Journal of Cleaner Production, 193, 759-770.

[18] Huang, S., Ding, D., \& Chen, Z. (2014). Entrepreneurial Leadership and Performance in C hinese New Ventures: A Moderated Mediation Model of Exploratory Innovation, Exploitative Innovation and Environmental Dynamism. Creativity and Innovation Management, 23(4), 453-471.

[19] Hueske, A.-K., Endrikat, J., \& Guenther, E. (2015). External environment, the innovating organization, and its individuals: A multilevel model for identifying innovation barriers accounting for social uncertainties. Journal of Engineering and Technology Management, 35, 45-70.

[20] Iovino, F., \& Tsitsianis, N. (2020). The Methodology of the Research. In Changes in European Energy Markets: Emerald Publishing Limited.

[21] Khalili, A. (2016). Linking transformational leadership, creativity, innovation, and innovationsupportive climate. Management Decision. 
[22] Kmieciak, R., \& Michna, A. (2018). Knowledge management orientation, innovativeness, and competitive intensity: evidence from Polish SMEs. Knowledge Management Research \& Practice, 16(4), 559572.

[23] Kmieciak, R., Michna, A., \& Meczynska, A. (2012). Innovativeness, empowerment and IT capability: evidence from SMEs. Industrial Management \& Data Systems.

[24] Lee, K. C., Lee, S., \& Kang, I. W. (2005). KMPI: measuring knowledge management performance. Information \& Management, 42(3), 469-482.

[25] Liao, S.-H., \& Wu, C.-c. (2010). System perspective of knowledge management, organizational learning, and organizational innovation. Expert Systems with Applications, 37(2), 1096-1103.

[26] Mafabi, S., Munene, J. C., \& Ahiauzu, A. (2015). Creative climate and organisational resilience: the mediating role of innovation. International journal of organizational analysis.

[27] Newman, A., Herman, H., Schwarz, G., \& Nielsen, I. (2018). The effects of employees' creative selfefficacy on innovative behavior: The role of entrepreneurial leadership. Journal of Business Research, 89, 1-9.

[28] Nonaka, I., \& Takeuchi, H. (1995). The knowledge-creating company: How Japanese companies create the dynamics of innovation: Oxford university press.

[29] Olsson, A., B. Paredes, K. M., Johansson, U., Olander Roese, M., \& Ritzén, S. (2019). Organizational climate for innovation and creativity-a study in Swedish retail organizations. The International Review of Retail, Distribution and Consumer Research, 29(3), 243-261.

[30] Ouakouak, M. L., \& Ouedraogo, N. (2017). ANTECEDENTS OF EMPLOYEE CREATIVITY AND ORGANISATIONAL INNOVATION: AN EMPIRICAL STUDY. International Journal of Innovation Management, 21(07), 1750060. doi:10.1142/S1363919617500608

[31] Overall, J. (2015). A conceptual framework of innovation and performance: The importance of leadership, relationship quality, and knowledge management. Academy of Entrepreneurship Journal, 21(2), 41.

[32] Park, Y. W., \& Hong, P. (2019). Innovation and Knowledge Creation Management in the Japanese Context. In Creative Innovative Firms from Japan (pp. 63-72): Springer.

[33] Paudel, S. (2019). Entrepreneurial leadership and business performance. South Asian Journal of Business Studies.

[34] Petrov, V., Ćelić, Đ., Uzelac, Z., \& Drašković, Z. (2020). Specific influence of knowledge intensive and capital intensive organizations on collaborative climate and knowledge sharing in SMEs. Strategic Management, 25(1), 3-11.

[35] Renko, M., El Tarabishy, A., Carsrud, A. L., \& Brännback, M. (2015). Understanding and measuring entrepreneurial leadership style. Journal of Small Business Management, 53(1), 54-74.

[36] Sekaran, U., \& Bougie, R. (2016). Research methods for business: A skill building approach: John Wiley \& Sons.

[37] Shadur, M. A., Kienzle, R., \& Rodwell, J. J. (1999). The relationship between organizational climate and employee perceptions of involvement: The importance of support. Group \& Organization Management, 24(4), 479-503.

[38] Slavković, M., \& Babić, V. (2013). Knowledge management, innovativeness, and organizational performance: Evidence from Serbia. Economic annals, 58(199), 85-107.

[39] Statistik, B. P. (2010). Profil Usaha Kecil dan Menengah Tidak Berbada Hukum Indonesia. In: Jakarta.

[40] Wahyono, W. (2019). The mediating effects of product innovation in relation between knowledge management and competitive advantage. Journal of Management Development.

[41] Wang, Z., \& Wang, N. (2012). Knowledge sharing, innovation and firm performance. Expert Systems with Applications, 39(10), 8899-8908. 